Article

\title{
Disaster Risk Reduction in Agriculture through Geospatial (Big) Data Processing
}

\author{
Tomáš Ǩezník ${ }^{1, *}$, Vojtěch Lukas ${ }^{2}$ (D), Karel Charvát ${ }^{3}$, Karel Charvát Jr. ${ }^{3}$, Zbyněk Křivánek ${ }^{3}$, \\ Michal Kepka ${ }^{4}$, Lukáš Herman ${ }^{1}$ and Helena Řezníková ${ }^{5}$ \\ 1 Department of Geography, Faculty of Science, Masaryk University, 61137 Brno, Czech Republic; \\ herman.lu@mail.muni.cz \\ 2 Department of Agrosystems and Bioclimatology, Faculty of Agronomy, Mendel University in Brno, \\ 61300 Brno, Czech Republic; vojtech.lukas@mendelu.cz \\ 3 Wirelessinfo, Cholinská 1048/19, 78401 Litovel, Czech Republic; charvat@wirelessinfo.cz (K.C.); \\ charvat_junior@wirelessinfo.cz (K.C.J.); krivanek@wirelessinfo.cz (Z.K.) \\ 4 Department of Geomatics, Faculty of Applied Science, University of West Bohemia, \\ 30100 Pilsen, Czech Republic; mkepka@kgm.zcu.cz \\ 5 Lesprojekt - služby s.r.o., Martinov 197, 27713 Záryby, Czech Republic; reznikova@lesprojekt.cz \\ * Correspondence: tomas.reznik@sci.muni.cz; Tel.: +420-549-49-4460
}

Academic Editors: Milan Konecny and Wolfgang Kainz

Received: 1 May 2017; Accepted: 2 August 2017; Published: 6 August 2017

\begin{abstract}
Intensive farming on land represents an increased burden on the environment due to, among other reasons, the usage of agrochemicals. Precision farming can reduce the environmental burden by employing site specific crop management practices which implement advanced geospatial technologies for respecting soil heterogeneity. The objectives of this paper are to present the frontier approaches of geospatial (Big) data processing based on satellite and sensor data which both aim at the prevention and mitigation phases of disaster risk reduction in agriculture. Three techniques are presented in order to demonstrate the possibilities of geospatial (Big) data collection in agriculture: (1) farm machinery telemetry for providing data about machinery operations on fields through the developed MapLogAgri application; (2) agrometeorological observation in the form of a wireless sensor network together with the SensLog solution for storing, analysing, and publishing sensor data; and (3) remote sensing for monitoring field spatial variability and crop status by means of freely-available high resolution satellite imagery. The benefits of re-using the techniques in disaster risk reduction processes are discussed. The conducted tests demonstrated the transferability of agricultural techniques to crisis/emergency management domains.
\end{abstract}

Keywords: precision farming; machinery telemetry; wireless sensor network; remote sensing

\section{Introduction}

Disaster Risk Reduction (DRR) is commonly defined as the attempt to reduce the damage caused by natural hazards like earthquakes, floods, droughts, and cyclones through the ethic of prevention [1-3]. The basic principle of DRR lies in systematic efforts to analyze and reduce factors of disasters. Typical examples in this respect could be reducing exposure to hazards, lowering the vulnerability of buildings, the wise management of land and the environment, the improvement of early warning, etc.

The most common DRR applications in the agricultural domain are related to water pollution and land management. These DRR applications are crucial from the point of view of scale; it is stated that agriculture is globally the single largest user of freshwater resources, each country using an average of $70 \%$ of all its surface water supplies, with an essential proportion of agricultural water being recycled back to surface water and/or groundwater [4]. The prevention of water pollution caused by 
agriculture is therefore a subject of (inter)national legislation, such as [5-9]. Land management related DRR applications most typically target (the prevention of) floods, droughts, and landslides [1]. It may be concluded that agricultural DRR applications aim at the preparedness phase of the DRR cycle [10].

The concept of so-called precision agriculture aims to minimize all the abovementioned risks. For instance, [11] identified three main goals of precision agriculture:

1. to optimize the use of available resources to increase the profitability and sustainability of agricultural operations;

2. to reduce negative environmental impacts;

3. to improve the quality of the working environment and social aspects of farming.

Precision farming relies on geospatial data and functionalities that are typically available through a Farm Management Information System (FMIS). Any FMIS may also be considered as a kind of Geographic Information System (GIS) as it provides answers to two basic questions: what has happened and where. We therefore also talk about site-specific management, which takes into consideration geospatial variabilities within fields and optimizes the production inputs, thus fulfilling the objectives of sustainable agriculture [12]. As indicated by [13], the site specific application of fertilizers and pesticides at the places where they are required leads to a reduction of (environmental) risks. Sensors are crucial in the development of precision agriculture because of their fixed costs and because they are able to make repeated small-scale measurements with respect to space and time [14].

The site-specific optimisation of cultivation activities is one of the ways of decreasing the environmental burden caused by agriculture. The authors of [15] claim that precision agriculture cannot completely compensate for these effects, but it can potentially reduce some of them.

The basic precondition for profitability through the implementation of precision agriculture techniques is the existence of small-scale in-field differences in factors relevant to plant development, such as variations in soil, fertilizer, and water availability.

Despite the disadvantages mentioned above, the usage of geospatial (Big) data in precision agriculture significantly contributes to the reduction and mitigation of phases of disaster risk in the following areas:

- it reduces the amount of nitrogen inserted into the ground and polluting (ground) waters;

- it reduces the contamination of soils by chemical residues after applications for plant protection;

- it reduces excessive fertilization;

- it reduces soil erosion and the consequent landslides as well as eutrophication of surface waters.

The objectives of this paper are to present the frontier approaches of geospatial (Big) data processing based on satellite and sensor data which both aim at DRR in agriculture. The published results are the key achievements of two European research projects, the Farm Oriented Open Data in Europe project (abbreviated as "FOODIE", funded between 2014 and 2017) and the Data-Driven Bioeconomy project (abbreviated as "DataBio", funded between 2017 and 2019). The DataBio project is a follow-up to the FOODIE project, targeting Big Data processing in agriculture, including disaster risk reduction.

\section{Methods}

Three geospatial techniques to support disaster risk reduction in the agricultural domain are presented in Sections 2.1-2.3. Farm machinery telemetry, wireless sensor networks, and periodic remote sensing are used for both water pollution and land management-related disaster risk reduction in the preparedness and mitigation phases.

\subsection{Farm Machinery Telemetry}

Telemetry is an automated communications process by which measurements and other data are collected at remote or inaccessible points and transmitted to receiving equipment for monitoring [16]. 
Agricultural machines produce a large amount of data during their work, which can be integrated into disaster risk reduction as well as into other domains. For more details on this topic, see [17-19].

Our solution consists of a set of hardware (e.g., the monitoring unit, GNSS [Global Navigation System of Systems] receiver) and software (e.g., ECU/CAN [Electronic Control Unit Controller Area Network] bus and RFID [Radio-Frequency Identification] interfaces as well as the user applications), designated as MapLogAgri. Teltonika FM5300 [20] was used as the commercial-off-the-shelf GNSS solution, while the rest of the development, including the monitoring unit, is the result of the FOODIE and DataBio projects. The following properties are available from MapLogAgri every two seconds (the administrator-defined interval, which can be customized): position, type of machine, fuel consumption, speed, motor revolutions per minute, type of machine coupled to the monitored vehicle (sowing machine, sprayer etc.) and many other technical parameters-including, for example, oil exchange interval. MapLogAgri in near real time also computes statistics per site/plot/management zone and / or per machine. For instance, the application of a pesticide in an inappropriate amount and/or at an inappropriate location (typically beyond the plot) generates an automatic alert to registered users of the MapLogAgri system. More information on agricultural machinery fleet monitoring is provided by [21]. In this research, a total of 9 tractors and 23 machines have been monitored continuously since March 2015.

The ISO (International Organization for Standardization) bus and ECU/CAN bus are used for communication on the sensor level of an agricultural machine. Note that the latest implementations of the ISO bus and ECU/CAN bus do not offer straightforward open communication as their predecessors did. It is an open question whether this is a consequence of a changing policy on the part of agricultural machine producers. Some have recently introduced a new business model according to which the farmer only rents agricultural machines. The license agreement prohibits a farmer from buying the machine. As a result, all the data measured remain the property of the agricultural machine producer. We have identified this change as a threat to the openness of machinery sensor monitoring.

\subsection{Wireless Sensor Networks}

Wireless sensor networks (WSN) allow the measurement of the dynamics of environmental characteristics related to crop growth, such as meteorological variables. It is another technology that can provide processed real-time field data from sensors physically distributed in fields [22-24]. Our development followed the principles of an infrastructure design for the seamless integration of wireless and wired sensors into information systems for precision agriculture described by [25]. An integrated open geospatial web service was implemented in order to acquire, integrate, process, and distribute monitoring information from the physical sensors to any system over the World Wide Web.

Agrometeorological monitoring was established in the form of a local WSN, distributed over selected fields and with a central meteorological station installed in the farmyard with the distribution of nodes within selected fields (Figure 1). The WSN consisted of four nodes with various sensors (see description in Table 1) and a gateway for data transfer via GPRS (General Packet Radio Station), both installed in spring 2015 within two farm fields with winter wheat and spring barley.

SensLog is our solution for collecting, storing, processing, analysing, and publishing sensor data. SensLog receives observations and measurements from individual gateways deployed in farm fields by means of a system of web services. The internet connections for the deployed gateways can be realized by a number of methods; therefore, SensLog provides for variable usage. SensLog is capable of storing the observations and positions of mobile sensors in the same way as for static sensors. Additional data sets can be provided by storing data in the database in different schemas. SensLog provides processing procedures and analytical functions to pre-process raw collected data or to detect alert events in operating sensor networks. Additional data sources can be involved in these analytical functions (e.g., the geometries of plots from LPIS- the Land Parcel Identification System, hydrography geometries, statistical data, zone pricing, etc.). 


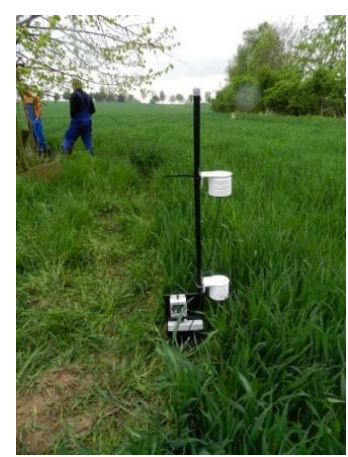

(a)

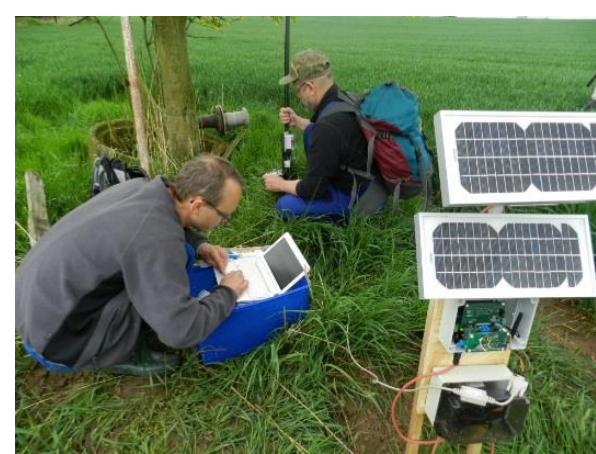

(b)

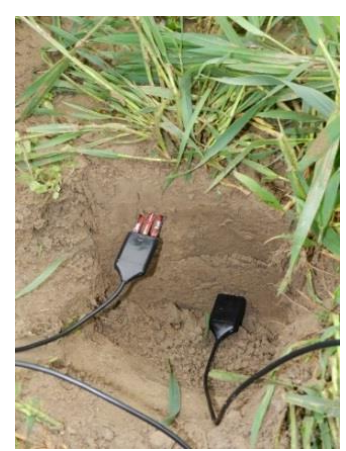

(c)

Figure 1. Sensor installations in various conditions: (a) field sensors in a field with winter wheat; (b) installation of a WSN gateway; (c) detailed installation of soil moisture sensors in the soil profile.

Table 1. Node sensors and meteorological sensors used for verification of the wireless sensor network on farm land

\begin{tabular}{cl}
\hline Node Sensors/Meteorological Stations & \multicolumn{1}{c}{ Description } \\
\hline Decagon VP-3 & $\begin{array}{l}\text { Sensor for the measurement of humidity, air temperature, and vapor } \\
\text { pressure. Mounted on a node pole under a radiation shield at the } \\
\text { height of the canopy stand or above. }\end{array}$ \\
\hline Decagon 5TM & $\begin{array}{l}\text { Sensor for the measurement of soil moisture, dielectric permittivity, } \\
\text { temperature, and volumetric water content moisture. Installed at a } \\
\text { soil depth of } 10 \text { and } 20 \mathrm{~cm} .\end{array}$ \\
\hline Vaisala WXT520 & $\begin{array}{l}\text { Multi-sensor for the measurement of air temperature, relative } \\
\text { humidity, barometric pressure, wind speed, wind direction, rainfall } \\
\text { precipitation, and rain and hail intensity. }\end{array}$ \\
\hline \multirow{2}{*}{ Decagon 5TM } & $\begin{array}{l}\text { Sensor for the measurement of soil moisture, dielectric permittivity, } \\
\text { temperature, and volumetric water content moisture. Installed at a } \\
\text { soil depth of } 10 \text { and } 20 \mathrm{~cm} .\end{array}$ \\
\hline
\end{tabular}

From the disaster risk reduction perspective, wireless sensor networks play a supportive role during the mitigation phase. Since our WSN architecture is an open one, any decision support system may re-use data measured by the WSN originally collected for agricultural reasons. The only condition is to apply the same standards as followed by our architecture, i.e., [26-28]. The Emergency Support System $[29,30]$ is an example of a system for disaster risk reduction that is capable of doing so.

\subsection{Periodic Remote Sensing}

The aim of our research was to prepare prescription maps for spatially variable applications of fertilizers and pesticides, estimated by the spectral measurement of crop parameters. Such an approach aims at minimizing risks related to inappropriate application, which can represent a water pollution hazard.

Periodic satellite remote sensing is suitable for the wide-ranging identification of spatial variability and for simultaneously capturing the dynamics of vegetation growth, both at a medium level of spatial resolution; such as in the case of Landsat 8 images $30 \mathrm{~m}$ per pixel, once per 16 days, or Landsat 7 with the same parameters. As a first step, Landsat-derived products of the ESPA (United States Geological Survey's Earth Resources Observation and Science Center Science Processing Architecture repository) were used. There were two options. The first option was to use Landsat satellite images with all multispectral bands included. The second option was to use only the processed vegetation indices NDVI (Normalized Difference Vegetation Index) and EVI (Enhanced Vegetation Index) as well as cloud identification by the CFmask algorithm. Both options were used, i.e., computations based on multispectral satellite data as well as ESPA products. No significant differences were found when comparing the outputs of both methods. 
It was demonstrated for the FOODIE and DataBio project pilot areas [31,32] that European Sentinel-2 data provide a valuable source for periodic satellite remote sensing, which is going to significantly shorten the temporal resolution, e.g., to about six days for most of Central Europe when combining Landsat and Sentinel data. Moreover, a combination of Sentinel 2/A, Sentinel 2/B, and Landsat data will allow satellite data to be obtained every three days for almost any location in Europe. Geospatial data does not necessarily mean Big, even if we talk about an average of 15.261 terabytes monthly for combined Sentinel 2/A, Sentinel 2/B, and Landsat data relevant to one farm, as revealed by DataBio project pilots [32]. The respective dynamics-e.g., every-three-day updates of such an amount of data-requires Big data approaches since 'traditional' non-distributed data storage systems and sequential processing mechanisms are insufficient. The conducted tests within the FOODIE and DataBio projects discovered that array-based databases are suitable for satellite data storage. On the other hand, PostgreSQL XL (Structured Query Language, eXtra Large)-i.e., a version for cloud-based solutions-was found to be insufficient for the storage and processing of computed potential yield zones. Zones of potential yield are areas with the same yield level within fields as the maximum yield that could be reached by a crop in given environments [33]. The database was not capable of handling dozens of terabytes of derived data. This issue was temporarily resolved by parallelizing storages and tasks as well as by reducing the number of indices and farms for which potential yield was computed.

A selection of satellite scenes from the past eight years was made for a particular farm area in order to collect cloud-free data related to the second half of the vegetation period. During the FOODIE project pilots [31], eight years was discovered as a sufficient period for diagnosing potential yield zones. Only data from the second half of the vegetation period are needed since they indicate the progress of the biomass. Potential yield was calculated for separate scenes as the relation of each pixel to the (index) mean value for the whole field. In the final step, all scenes were combined and the median value of potential yield was calculated. Landsat 8 , Sentinel-2, and MODIS data were used as the inputs for the indices as defined by [34-36].

The abovementioned indices need to be computed from relevant satellite data. Information on farmer's parcels (plots) is the second input since it defines relatively homogenous areas from the crop point of view; one plot parcel usually contains one crop type in one vegetation season. The abovementioned indices are computed as variabilities within each plot. Potential yield is then computed for each plot from underlying vegetation, water, and moisture indices through empirical Bayesian Kriging interpolation [37] and smoothed to a spatial resolution of $5 \mathrm{~m}$. For instance, such computation for the country of Luxembourg (about $2500 \mathrm{~km}^{2}$, i.e., $1000 \mathrm{sq} \mathrm{mi}$ ) with 92,000 plots took two weeks at the Poznań Supercomputing and Networking Center (64 computer nodes in cloud; each node with processor $2 \times$ E5 2670 v2/2697 v3 @ 2.6 GHz, operation memory 256 GB and storage 40 TB connected via Fibre Channel, 50 TB Ceph via 10 Gbit ethernet).

Potential yield presents values in percentages, identifying places with, for example, $60 \%$ or $140 \%$ potential yield in comparison to the average value for a plot. A farmer then knows that some areas are less productive and that less fertilizer/pesticide has to be applied at those locations, and vice versa.

Zones of potential yield are another form of derived data from periodic remote sensing. Yield is the integrator of landscape and climatic variability and, as such, provides useful information for identifying management zones as defined by [37,38]. This represents the basic delineation of management zones for site specific crop management, which is usually based on yield maps over the past few years. The presence of complete series of yield maps for all fields is rare; thus, remotely sensed data are analyzed to determine the field variability of crops through vegetation indices.

A tailored Web Processing Service (WPS), as defined by an implementation specification of the Open Geospatial Consortium [39], is being developed. The proof-of-concept software solution was based on ArcGIS Desktop 10.3.1 developed by the ESRI (Environmental System Research Institute, Redlands, CA, USA) corporation. The development of the tailored WPS is motivated by the amount of data as well as by the complexity of processing. 


\section{Results}

\subsection{Farm Machinery Telemetry}

The farm machinery monitoring conducted in this research has proven the need for a robust cloud-based geospatial solution since, in this case, 10 megabytes of data were generated each day when monitoring was conducted on a real commercial Czech farm with 1284 hectares. Also, in this case, the major challenges were the amount and dynamics of measured data. Since the Luxembourg plots and the Czech plots are tended by a similar number of tractors and application machines, farm machines in the small country of Luxembourg would generate about one gigabyte of telemetric data per day.

The primary aim of farm machinery monitoring from the DRR perspective lies in the automatic capacity to send alerts to any decision support system respecting geospatial standards. The alerting service, as depicted in Figure 2, was developed in the FOODIE project as an extension of the MapLogAgri [40]. It provides, in an automatic manner, diverse notifications and reports for its users (farmers, decision makers, environmental agencies, etc.) based on data collected and stored in its various information repositories. The alerting service is an adaptation and enhancement of the notification component developed in the European FP6 (Framework Program) DEWS (Distant Early Warning System) project [41]. The modifications performed within the FOODIE project enhance functionality for REST (REpresentational State Transfer) interface [42] support as well as provide the possibility to forward notifications to iOS and Android based mobile devices. Registered users may subscribe to different 'topics' defined by the user in a customized way, e.g., in a specific language when using terms from a specific community (through a thesaurus). Stakeholders in disaster risk reduction processes may therefore use the developed notification service as an input and/or re-use the notification service itself for any crisis/emergency management system, i.e., a domain for which it was originally developed.

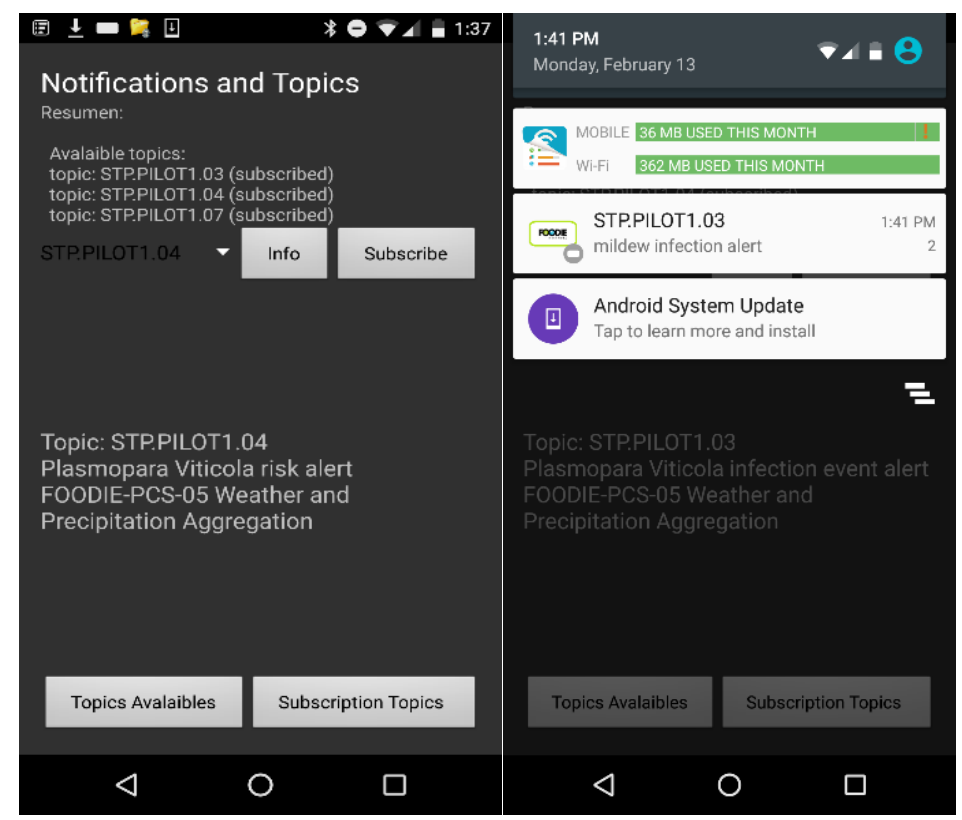

Figure 2. User interface of the developed alerting service: a notification received on a smartphone (the left image) and the content of a notification in a structure customized in advance by a user (the right image).

The secondary aim of farm machinery telemetry lies in the area of the optimized application of fertilizers and pesticides, i.e., the prevention of risks resulting from their inappropriate application. We may identify several relations between the results of periodic remote sensing on the one hand, and farm machinery telemetry data on the other. For example, according to the developed yield potential 
maps, it was discovered via MapLogAgri that vehicles have the highest fuel consumption in less productive areas.

\subsection{Wireless Sensor Networks}

The database schema for SensLog follows the ISO 19156 Observations and Measurements concept [26]. Extended functionality was implemented in the database model to fulfil all farmer requirements. Data are stored in a PostgreSQL (open source) database in version 9.3.6 together with its spatial extension PostGIS in version 2.1.0. In addition, the developed database schema has been replicated in the Cloud (Infrastructure as a Service) provided by the Poznań Supercomputing and Networking Center (Poznan, Poland) using OpenStack as an Open Source Cloud Computing Software.

As shown in Figure 3, communication between sensors and SensLog is possible through two interfaces, SOS 1.0.0 and/or REST API. The provider module controls communication between the two defined interfaces and (SensLog) core of the application, i.e., by modifications of the periodicity of sensor measurements, battery status, or measured features. The web GUI (Graphical User Interface) was developed for the user-friendly control of available sensors and their modifications. The SensLog core enables the business logic of the SensLog application, i.e., it can receive sensor data, store them in a database, or provide aggregated measurements or statistics derived from measured data to a user through the Feeder module and the REST API. SensLog is an open and extensible application; for instance, MapLogAgri is one of its specific extensions.

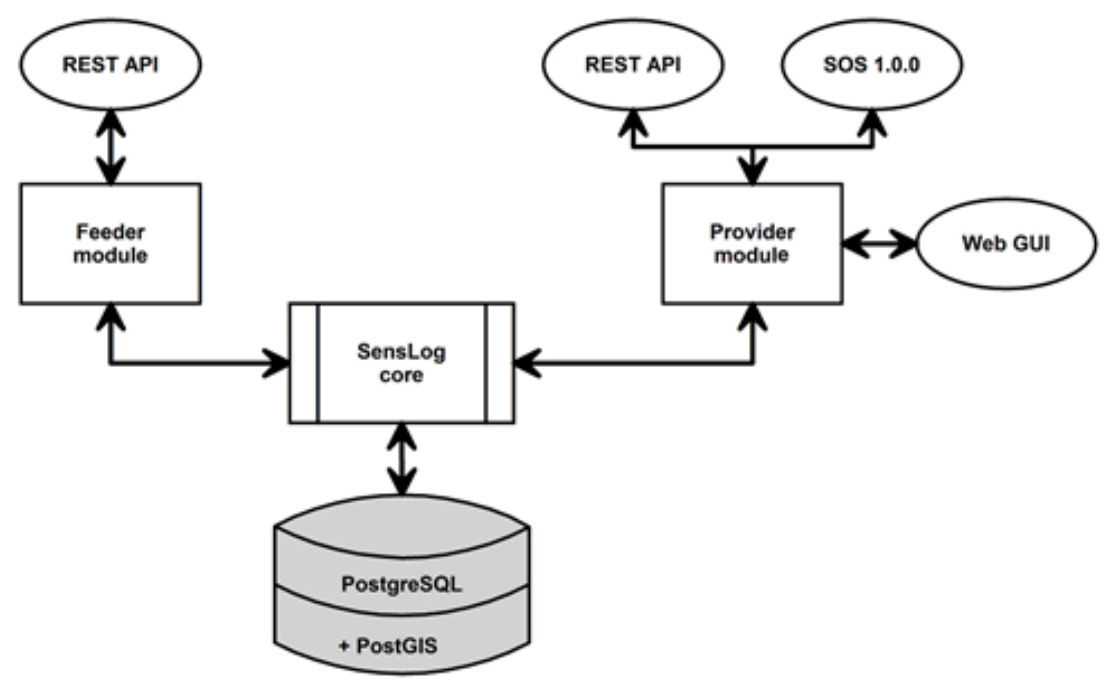

Figure 3. Overview diagram of SensLog application and communication interfaces.

A system of web services in several forms was developed to provide a variety of methods for data publishing. RESTful services publishing data in JSON format are used for operational usage and communication with other components. Services based on OGC Sensor Observation Service 1.0.0 core methods [26] are used for the standardized publishing of data.

From the disaster risk reduction perspective, SensLog is a platform for any sensor-based data that are ready to be integrated into a decision support system following the geospatial [26-28] and/or IT (Information Technology) mainstream standards [42]. Also, SensLog could be re-used in crisis/emergency management as application for any kind of sensor measurement, as it is provided through an open BSD (Berkley Software Distribution) license [43]. The following test was performed in order to verify the transferability of the SensLog application. The integration of geospatial data on air quality, including levels of toxic compounds, from the FP7 project called CITI-SENSE [44] was achieved in September 2016. Within a timeframe of two working days, we succeeded in integrating all sensor measurements collected during the three-year-long CITI-SENSE project (approximately 20 GB 
of sensor data). Newly arriving data from sensors connected with a smartphone through Bluetooth technology were, after two days of modification, operated by the SensLog application.

\subsection{Periodic Remote Sensing}

The potential yield concept, as presented in this paper, aims at establishing a general model for potential yield zones for almost any kind of crop. However, such universality comes at a price. The model is capable of expressing significant spatial variations for a given crop yield on a particular plot by distinguishing three kinds of values: below average, average, and above average. However, the model depicts spatial variations within a plot, and therefore it could be misleading when trying to compare yield zones between plots. Altogether, we conclude that some areas in a plot have significantly lower productivity than others and take such information into the decision making process. However, we cannot determine whether it is better to produce a crop on plot A or plot B.

The concept of potential yield was successfully validated. Altogether, in $80 \%$ of the areas of the evaluated farm-Tršická zemědělská in the Czech Republic-the calculated potential yield turned out to be the same as the actual yield. Note that such a situation is very rare, since the FOODIE and DataBio projects found only two farms out of one thousand that were capable of producing yield results in the form of maps with sufficient detail (i.e., detail of management zones within a plot).

The evaluated farm lies in the Czech Republic and its acreage is about 1284 hectares. The transferability of the potential yield concept was, among others, verified for the country of Luxembourg. A simple application depicting potential yield from satellite images and re-computing the appropriate amount of fertilizer may be found under the URL http:/ / foodie-data.wirelessinfo.cz/php/ foodie_luc/ (see Figure 4). The aim of this application is to minimize the amount of fertilizer inserted into the ground and therefore to provide a basis for the prevention and/or reduction of disaster risk in cases of water pollution [45]. The developed application is an open one, i.e., available to all users.

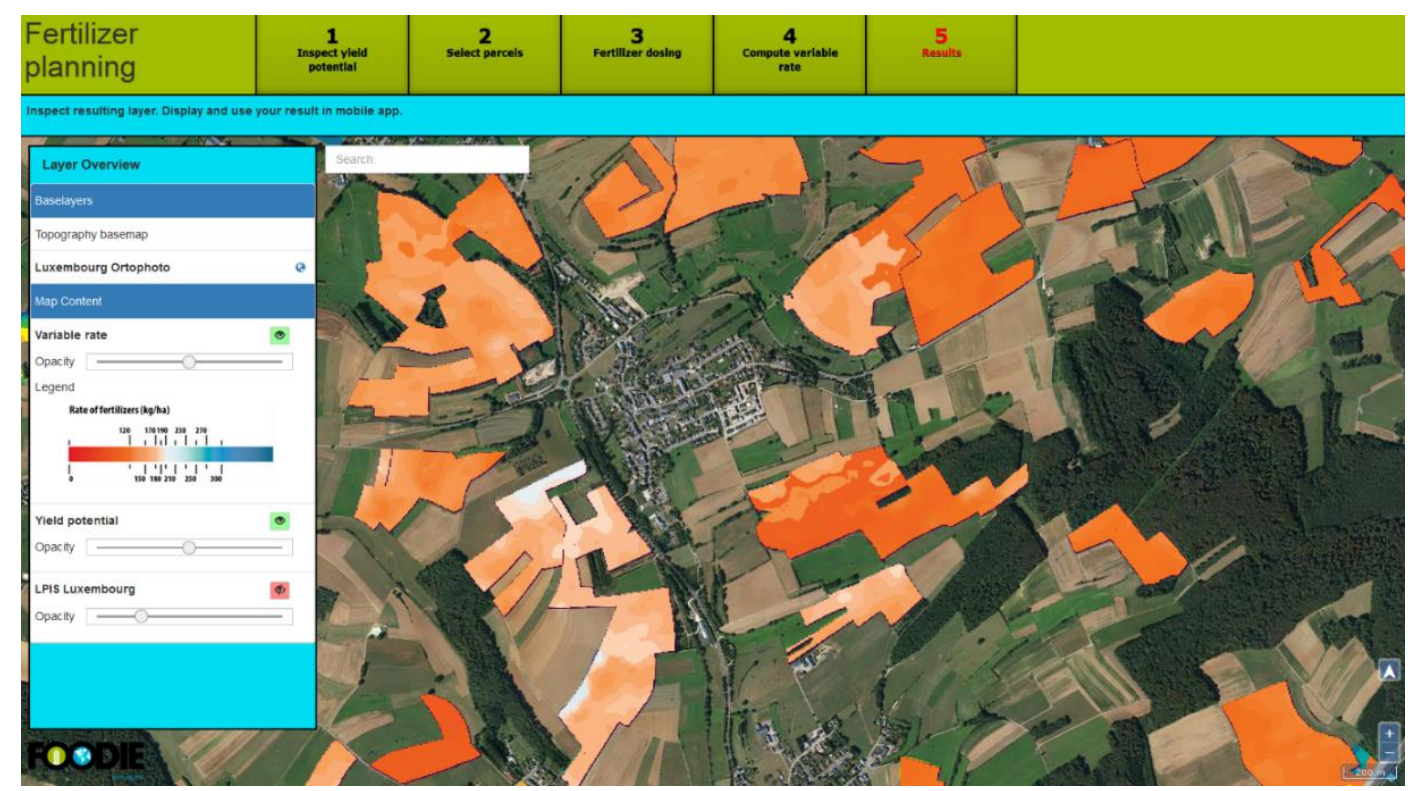

Figure 4. Fertilizer planning application based on yield potential zones as a tool for farmers to minimize the environmental burden as well as risk of water pollution.

Ongoing research follows two main directions. The first aims at optimizing the algorithm to increase the probability of yield prediction up to $90 \%$. The second focuses on the implementation of potential yield calculation as an open web service, namely as an OGC Web Processing Service, as described in Section 2.3. 


\section{Discussion and Conclusions}

The three presented techniques-i.e., farm machinery telemetry, wireless sensor networks, and periodic remote sensing-were developed primarily for the domain of agricultural applications. This paper describes the transferability of the developed techniques into the domain of crisis/emergency management. All three techniques generate massive amounts of data that are re-usable in disaster risk reduction processes. The importance of the measured and observed data is emphasized by three aspects:

1. Data are available for large, typically rural areas, where, usually, such data sources are limited even though they are valuable for decision making. Indeed, crisis situations in sparsely populated rural areas, such as groundwater contamination, often have consequences in cities. Therefore, it is important that data also be available from rural areas.

2. Alerting and notification services are capable of being connected with decision support systems in order to provide relevant information automatically derived from measured and observed data in near real time (at the very beginning of the mitigation phase).

3. Risks created by agricultural activities, such as risks of water pollution or landslides, are minimized through the combination of the three above-described techniques (in the prevention phase).

Moreover, the developed techniques are re-usable as building blocks in the modular architecture of decision making systems and/or in any other relevant crisis/emergency management systems. The transferability of the developed applications was successfully verified in two use cases. The first was dedicated to air quality measurement through smartphones. Here, the SensLog application was ready to adopt historical air quality data as well as assimilate newly incoming air quality measurements. The second use case demonstrated the transferability of the alerting system between the domains of emergency/crisis management and precision agriculture. The alerting system is available for customized notifications on user-defined topics.

The described combination of all three techniques has been registered under the GEOSS (Global Earth Observation System of Systems) Architecture Implementation Pilot (Phase 8) in order to help address the wide variety of demands that are primarily concerned with agriculture and water pollution monitoring as well as pollution risk prevention or reduction.

Ongoing research focuses on developing more efficient storage and processing capabilities in order to increase the performance of the provided open web services for decision support systems. The improvement of potential yield computations is also a subject of further research.

Acknowledgments: This project has received funding from the European Union's Horizon 2020 research and innovation program under grant agreement No. 732064 called "Data-Driven Bioeconomy" (DataBio), the European Union's Seventh Framework Program for research, technological development, and demonstration under grant agreement No. 621074 titled "Farm-Oriented Open Data in Europe" (FOODIE) and the project of Masaryk University under grant agreement No. MUNI/A/1419/2016 called "Integrated Research of Environmental Changes in Earth's Sphere II".

Author Contributions: Tomáš Řezník set the overall architecture of the developed applications including data modelling and processing definitions; Vojtěch Lukas and Karel Charvát conceived and designed the experiments; Karel Charvát junior, Zbyněk Křivánek, and Helena Řezníková performed the experiments; Michal Kepka developed the SensLog application; Lukáš Herman defined (cartographic) visualizations.

Conflicts of Interest: The authors declare no conflict of interest.

\section{References}

1. What Is Disaster Risk Reduction? United Nations Systems for Disaster Risk Reduction (UNISDR). Available online: https: / / www.unisdr.org/who-we-are/what-is-drr (accessed on 9 June 2017).

2. Twigg, J. Disaster Risk Reduction, 2nd ed.; Humanitarian Practice Network; Overseas Development Institute: London, UK, 2015; p. 382.

3. Konecny, M.; Reinhardt, W. Early warning and disaster management: The importance of geographic information (Part A). Int. J. Digit. Earth 2010, 3, 217-220. [CrossRef] 
4. AQUASTAT-FAO's Information System on Water and Agriculture. Available online: http://www.fao.org/ $\mathrm{nr} /$ water/aquastat/main/index.stm (accessed on 9 June 2017).

5. United States Environmental Protection Agency 2015 Summary of the Clean Water Act 33 U.S.C. §1251 et seq. Available online: http:/ / www2.epa.gov/laws-regulations/summary-clean-water-act (accessed on 9 June 2017).

6. European Commission 1991 Council Directive 91/676/EEC of 12 December 1991 Concerning the Protection of Waters against Pollution Caused by Nitrates from Agricultural Sources. Available online: http:/ / eur-lex. europa.eu/legal-content/EN/TXT/HTML/?uri=CELEX:31991L0676\&from=EN (accessed on 9 June 2017).

7. European Commission 2012 the Common Agricultural Policy: A Partnership between Europe and Farmers. Available online: http:/ / ec.europa.eu/agriculture/cap-overview/2012_en.pdf (accessed on 9 June 2017).

8. European Commission 2000 Directive 2000/60/EC of the European Parliament and of the Council of 23 October 2000 Establishing a Framework for Community Action in the Field of Water Policy. Available online: http:/ / eur-lex.europa.eu/legal-content/EN/TXT/HTML/?uri=CELEX:32000L0060\&from=EN (accessed on 9 June 2017).

9. Ministry of Water Resources of the People's Republic of China 2015 Law of the People's Republic of China on the Prevention and Control of Water Pollution. Available online: http://www.mwr.gov.cn/english/laws. html (accessed on 9 June 2017).

10. Twigg, J. Disaster Risk Reduction: Mitigation and Preparedness in Development and Emergency Programming, 1st ed.; Humanitarian Practice Network; Overseas Development Institute: London, UK, 2004; p. 377.

11. Gebbers, R.; Adamchuk, V.I. Precision agriculture and food security. Science 2010, 327, 828-831. [CrossRef] [PubMed]

12. Corwin, D.L.; Plant, R.E. Applications of apparent soil electrical conductivity in precision agriculture. Comput. Electron. Agric. 2005, 46, 1-10. [CrossRef]

13. Bongiovanni, R.; Lowenberg-Deboer, J. Precision agriculture and sustainability. Precis. Agric. 2004, 5, 359-387. [CrossRef]

14. Pierce, F.J.; Nowak, P. Aspects of precision agriculture. Adv. Agron. 1999, 67, 1-85.

15. Rösch, C.; Dusseldorp, M.; Meyer, R. Precision Agriculture: 2. Bericht zum ta-Projekt Moderne Agrartechniken und Produktionmethoden-Ökonomische und Ökologische Potenziale; Büro für Technikfolgen-Abschätzung beim Deutschen Bundestag (TAB): Berlin, Germany, 2005; Volume 106, p. 204.

16. Telemetry: Summary of Concept and Rationale. Available online: http://adsabs.harvard.edu/abs/1987STIN. .8913455 (accessed on 12 June 2017).

17. Fountas, S.; Sorensen, C.G.; Tsiropoulos, Z.; Cavalaris, C.; Liakos, V.; Gemtos, T. Farm machinery management information system. Comput. Electron. Agric. 2015, 110, 131-138. [CrossRef]

18. Steinberger, G.; Rothmund, M.; Auernhammer, H. Mobile farm equipment as a data source in an agricultural service architecture. Comput. Electron. Agric. 2009, 65, 238-246. [CrossRef]

19. Kroulík, M.; Kvíz, Z.; Kumhála, F.; Hůla, J.; Loch, T. Procedures of soil farming allowing reduction of compaction. Precis. Agric. 2011, 12, 317-333. [CrossRef]

20. Teltonika FM5300 User Manual v3.59. Available online: www.teltonika.lt/?media_dl=4075 (accessed on 12 June 2017).

21. Řezník, T.; Kepka, M.; CHarvát, K.; Charvát, K., Jr.; Horáková, Š.; Lukas, V. Challenges of agricultural monitoring: Integration of the Open Farm Management Information System into GEOSS and Digital Earth. In IOP Conference Series: Earth and Environmental Science, 1st ed.; van Proosdij, D., Millward, H., Werle, D., Eds.; Institute of Physics Publishing: Halifax, NS, Canada, 2016; Volume 34, p. 8.

22. Akyildiz, I.F.; Su, W.; Sankarasubramaniam, Y.; Cayirci, E. Wireless sensor networks: A survey. Comput. Netw. 2002, 38, 393-422. [CrossRef]

23. Wang, N.; Zhang, N.; Wang, M. Wireless sensors in agriculture and food industry-Recent development and future perspective. Comput. Electron. Agric. 2006, 50, 1-14. [CrossRef]

24. Kubicek, P.; Kozel, J.; Stampach, R.; Lukas, V. Prototyping the visualization of geographic and sensor data for agriculture. Comput. Electron. Agric. 2013, 97, 83-91. [CrossRef]

25. Chen, N.; Zhang, X.; Wang, C. Integrated open geospatial web service enabled cyber-physical information infrastructure for precision agriculture monitoring. Comput. Electron. Agric. 2015, 111, 78-91. [CrossRef]

26. International Organization for Standardization. ISO 19156:2011 Geographic Information-Observations and Measurements, 1st ed.; International Organization for Standardization: Geneva, Switzerland, 2011; p. 46. 
27. Na, A.; Priest, M. Sensor Observation Service—Version 1.0.0, 1st ed.; Na, A., Priest, M., Eds.; Open Geospatial Consortium: Wayland, MA, USA, 2007; p. 105.

28. Botts, M. OpenGIS ${ }^{\circledR}$ Sensor Model Language (SensorML) Implementation Specification-Version 1.0.0, 1st ed.; Botts, M., Ed.; Open Geospatial Consortium: Wayland, MA, USA, 2007; 180 p.

29. Reznik, T.; Horakova, B.; Szturc, R. Geographic Information for Command and Control Systems Demonstration of Emergency Support System. In Intelligent Systems for Crisis Management: Geo-Information for Disaster Management (GI4DM) 2012_Lecture Notes in Geoinformation and Cartography, 1st ed.; Zlatanova, S., Dilo, A., Peters, R., Scholten, H., Eds.; Springer: Berlin, Germany, 2013; pp. 263-275.

30. Reznik, T.; Horakova, B.; Szturc, R. Advanced methods of cell phone localization for crisis and emergency management applications. Int. J. Digit. Earth 2015, 8, 259-272. [CrossRef]

31. FOODIE Project Consortium. D5.1.2: Pilots Description and Requirements Elicitation Report. Internal Project Document 2015. p. 205. Available online: www.foodie-project.eu/public/20161007091031.pdf (accessed on 6 August 2017).

32. DataBio Project Consortium. D1.1: Agricultural Pilot Definition. Internal Project Document 2017 (under review). Available online: www.databio.eu/wp-content/uploads/2017/05/DataBio_D1.1-AgriculturePilot-Definition_v1.0_2017-06-30_LESPRO.pdf (accessed on 6 August 2017).

33. Kleinjan, J.; Clyde, D.E.; Carlson, C.G.; Clay, S.A. Productivity zones from multiple years of yield monitor data. In GIS Applications in Agriculture; Pierce, F.J., Clay, D., Eds.; CRC Press: Boca Raton, FL, USA, 2007; pp. 65-70.

34. Reznik, T.; Lukas, V.; Charvat, K.; Charvat, K., Jr.; Horakova, S.; Krivanek, Z.; Herman, L. Monitoring of In-Field Variability for Site Specific Crop Management through Open Geospatial Information. In International Archives of the Photogrammetry Remote Sensing and Spatial Information Sciences, 1st ed.; Halounova, L., Safar, V., Raju, P.L.N., Planka, L., Zdimal, V., Kumar, T.S., Faruque, F.S., Kerr, Y., Ramasamy, S.M., Comiso, J., et al., Eds.; Copernicus Gesselschaft MBH: Göttingen, Germany, 2016; pp. 1023-1028.

35. Palma, R.; Reznik, T.; Esbri, M.; Charvat, K.; Mazurek, C. An INSPIRE-Based Vocabulary for the Publication of Agricultural Linked Data. Ontol. Eng.-Lect. Notes Comput. Sci. 2016, 9557, 124-133. [CrossRef]

36. Reznik, T.; Charvat, K., Jr.; Charvat, K.; Horakova, S.; Lukas, V.; Kepka, M. Open Data Model for (Precision) Agriculture Applications and Agricultural Pollution Monitoring. In Proceedings of the Enviroinfo and ICT for Sustainability 2015, Copenhagen, Denmark, 7-9 September 2015; Johannsen, V.K., Jensen, S., Wohlgemuth, V., Preist, C., Eriksson, E., Eds.; Atlantis Press: Paris, France, 2015; Volume 22, pp. 97-107.

37. Evans, L.T.; Fischer, R.A. Yield Potential: Its Definition, Measurement, and Significance; Crop Science Society of America: Madison, WI, USA, 1999; Volume 39, pp. 1544-1551.

38. Le, N.D.; Zidek, J.V. Interpolation with uncertain spatial covariances: A Bayesian alternative to Kriging. J. Multivar. Anal. 1992, 43, 351-374. [CrossRef]

39. Schutt, P. OpenGIS ${ }^{\circledR}$ Web Processing Service—Version 1.0.0, 1st ed.; Schutt, P., Ed.; Open Geospatial Consortium: Wayland, MA, USA, 2007; p. 88.

40. FOODIE Project Consortium. D4.3.3 Event-Based Notification Services; Internal Project Document 2017. Available online: www.foodie-project.eu/public/20170614142800.pdf (accessed on 6 August 2017).

41. EU FP6 DEWS (Distant Early Warning System) Project. Available online: http://www.dews-online.org (accessed on 9 June 2017).

42. Web Services Architecture: W3C Working Group Note 11 February 2004. Available online: https://www.w3. org/TR/2004/NOTE-ws-arch-20040211/\#relwwwrest (accessed on 14 June 2017).

43. The 3-Clause BSD License I Open Source Initiative. Available online: https://opensource.org/licenses / BSD-3-Clause (accessed on 14 June 2017).

44. CITI-SENSE: Development of Sensor-Based Citizens' Observatory Community for Improving Quality of Life in Cities. Available online: http:/ / www.citi-sense.eu/ (accessed on 14 June 2017).

45. Hrebicek, J.; Konecny, M.; Kolar, M. Geoinformation Support for Water Disaster Situations. In Decision Support for Natural Disasters and Intentional Threats to Water Security, 1st ed.; Illangasekare, T.H., Mahutova, K., Barich, J.J., Eds.; Springer: Dordrecht, The Netherlands, 2009; pp. 179-189.

(C) 2017 by the authors. Licensee MDPI, Basel, Switzerland. This article is an open access article distributed under the terms and conditions of the Creative Commons Attribution (CC BY) license (http:/ / creativecommons.org/licenses/by/4.0/). 